\title{
Penerapan Teknik Bagging Berbasis Naïve Bayes untuk Seleksi Penerimaan Mahasiswa
}

\author{
Yum Leifita Nursimpati ${ }^{1}$, Aries Saifudin ${ }^{2}$ \\ Teknik Informatika, Universitas Pamulang, Tangerang Selatan, Indonesia \\ e-mail: ${ }^{1}$ yumleifita@ gmail.com, ${ }^{2}$ aries.saifudin@ unpam.ac.id
}

\begin{abstract}
Students who graduate not on time create an imbalanced ratio between lecturers and students. The current selection system is ineffective because it has not been able to detect prospective students who have the possibility of not being able to complete their education on time so that many students who are accepted do not graduate on time and leave without completing their education. This condition causes a decrease in performance of study programs and institutions. The classification algorithm can use for classifying new students as graduate timely or not. Naïve Bayes classification algorithm can use to classify data in certain classes, using the history of alumni of informatics engineering at Pamulang university as training data and prospective student data as test data. Some attributes used to determine which label class to graduate on time and not on time are gender, school majors, year difference, math grades, English, Indonesian. To improve the results of the classification of Naïve Bayes, Bagging (Bootstrap Aggregating) technique is used. From the test results of the alumni dataset, the informatics study program using bagging techniques as an optimization of the Naïve Bayes classification algorithm has a lower failure rate than without using bagging techniques. The results of the calculation of performance data using bagging techniques can increase accuracy by $2.381 \%$ and AUC by $1.470 \%$ on the student graduation prediction model for new student selection using the Naïve Bayes classification.
\end{abstract}

Kata kunci: Bagging, Data Mining, Naïve Bayes, Student Selection

\section{Pendahuluan}

Seleksi mahasiswa baru adalah acuan utama perguruan tinggi dalam memilah-milah calon mahasiswa sesuai dengan syarat yang ditentukan oleh perguruan tinggi. Penyeleksian mahasiswa baru dilakukan agar mendapatkan calon mahasiswa yang berkualitas. Mahasiswa yang berkualitas akan lulus tepat waktu sehingga membuat kualitas yang baik bagi perguruan tinggi, hal ini dapat meningkatkan akreditasi perguruan tinggi. Perguruan tinggi harus memiliki dan menerapkan kebijakan tentang rekrutmen dan seleksi mahasiswa baru, serta pengelolaan lulusan sebagai satu kesatuan mutu yang terintegrasi, dan menyelenggarakan kegiatan akademik untuk mewujudkan visi, melaksanakan misi, dan mencapai tujuan melalui strategi-strategi yang dikembangkan (BAN-PT, 2011). Upaya perguruan tinggi untuk memperoleh mahasiswa yang bermutu yaitu melalui sistem dan program rekrutmen atau seleksi penerimaan mahasiswa baru.

Universitas Pamulang adalah salah satu perguruan tinggi swasta yang banyak diminati oleh calon mahasiswa, khususnya program studi Teknik Informatika. Mengingat tujuan dari universitas Pamulang yaitu memberikan pendidikan dengan biaya yang murah agar semua kalangan dapat mengenyam pendidikan sampai ke jenjang sarjana. Karena hal ini, maka banyak calon mahasiswa yang coba-coba kuliah sehingga tidak meneruskan studi sampai selesai. Saat ini penerimaan mahasiswa baru di universitas Pamulang dilakukan dengan cara yang kurang efektif dan rumit. Seleksi mahasiswa baru saat ini memerlukan waktu yang lama untuk memutuskan diterima atau tidaknya calon mahasiswa serta memerlukan biaya yang lebih banyak untuk mencetak soal ujian. Sistem yang ada saat ini tidak efektif sehingga banyak mahasiswa yang lulus tidak tepat waktu. Hal ini menyebabkan ketidakseimbangan antara mahasiswa dengan dosen pengajar, mengingat bahwa banyaknya calon mahasiswa yang diterima setiap semesternya. Untuk mengatasi masalah tersebut akan digunakan teknik data mining untuk mengklasifikasi calon mahasiswa menggunakan metode klasifikasi. Teknik data mining dan machine learning dapat digunakan untuk memprediksi berdasarkan data-data masa lalu (Saifudin, 2018).

Untuk melakukan seleksi penerimaan mahasiswa baru dapat menggunakan algoritma klasifikasi nä̈ve bayes (Arti, 2009). Di mana akan 
dilakukan analisis untuk memperoleh informasi terhadap studi kasus penerimaan mahasiswa baru berdasarkan histori alumni pada program studi Teknik Informatika. Naive Bayes dapat melakukan klasifikasi dengan metode probabilitas dan statistik, yaitu memprediksi peluang di masa depan berdasarkan pengalaman di masa sebelumnya (Bustami, 2013). Algoritma Nä̈ve Bayes Classifier bertujuan untuk melakukan klasifikasi data pada kelas tertentu. Unjuk kerja pengklasifikasi diukur dengan nilai predictive accuracy (Zhang \& Su, 2006). Kelemahan data mining terdapat pada imbalance class yang merupakan suatu masalah atau tantangan karena biasanya mesin learning akan menghasilkan suatu akurasi prediksi yang baik terhadap kelas data latih yang banyak (kelas mayor), sedangkan untuk kelas data latih yang sedikit (kelas minor) akan dihasilkan akurasi prediksi yang buruk (Baizal, Bijaksana, \& Nasihati, 2009).

Dalam data mining terdapat dua metode untuk meningkatkan tingat akurasi prediksi dan ketepatan dalam klasifikasi yaitu Boosting dan Bootstrap Aggregating (Bagging) (Wirayuda, Hidayat, \& Shaufiah, 2010). Pemilihan metode bagging (Bootstrap Aggregating) sangat tepat untuk melakukan klasifikasi pada dataset. Teknik Bagging merupakan metode yang dapat memperbaiki hasil dari algoritma klasifikasi machine learning (Wicaksono, Oranova S, \& Sawosri, 2010). Dengan penerapan teknik ini maka hasil klasifikasi ataupun prediksi terhadap data memiliki tingkat kegagalan yang lebih rendah.

Berdasarkan uaraian pada latar belakang dapat diidentifikasikan beberapa masalah sebagai berikut: mahasiswa yang lulus tidak tepat waktu membuat ketidakseimbangan antara dosen dan mahasiswa mengingat banyaknya mahasiswa baru yang diterima tiap semesternya, sistem seleksi saat ini tidak efektif karena banyak mahasiswa yang tidak lulus tepat waktu dan keluar tanpa menyelesaikan pendidikanya, pengklasifikasian Naïve Bayes dapat digunakan untuk memprediksi (menyeleksi) calon mahasiswa, tetapi hasilnya belum akurat.

Tujuan dari penelitian ini adalah menerapkan teknik bagging untuk memanipulasi data training, agar kinerja algoritma pengklasifikasi (Nä̈ve Bayes) pada seleksi penerimaan mahasiswa baru dapat meningkat.

\section{Penelitian Terkait}

Kelemahan metode Nä̈ve Bayes terdapat pada imbalance class, dimana akan menghasilkan suatu akurasi prediksi yang baik terhadap kelas data latih yang banyak (kelas mayor), sedangkan untuk kelas data latih yang sedikit (kelas minor) akan dihasilkan akurasi prediksi yang buruk (Baizal, Bijaksana, \& Nasihati, 2009). Data latih yang tidak konsisten dapat mempengaruhi hasil dari metode Naïve Bayes.

Dalam penelitian ini diusulkan menggunakan teknik bagging sebagai perbaikan hasil dari metode Nä̈ve Bayes. Ini dikarenakan teknik Bagging merupakan metode yang dapat memperbaiki hasil dari algoritma klasifikasi machine learning (Wicaksono, Oranova S, \& Sawosri, 2010).

Berikut ini adalah diagram alur metode Naïve Bayes dan Naïve Bayes dengan Bagging dalam menyeleksi mahasiswa baru.

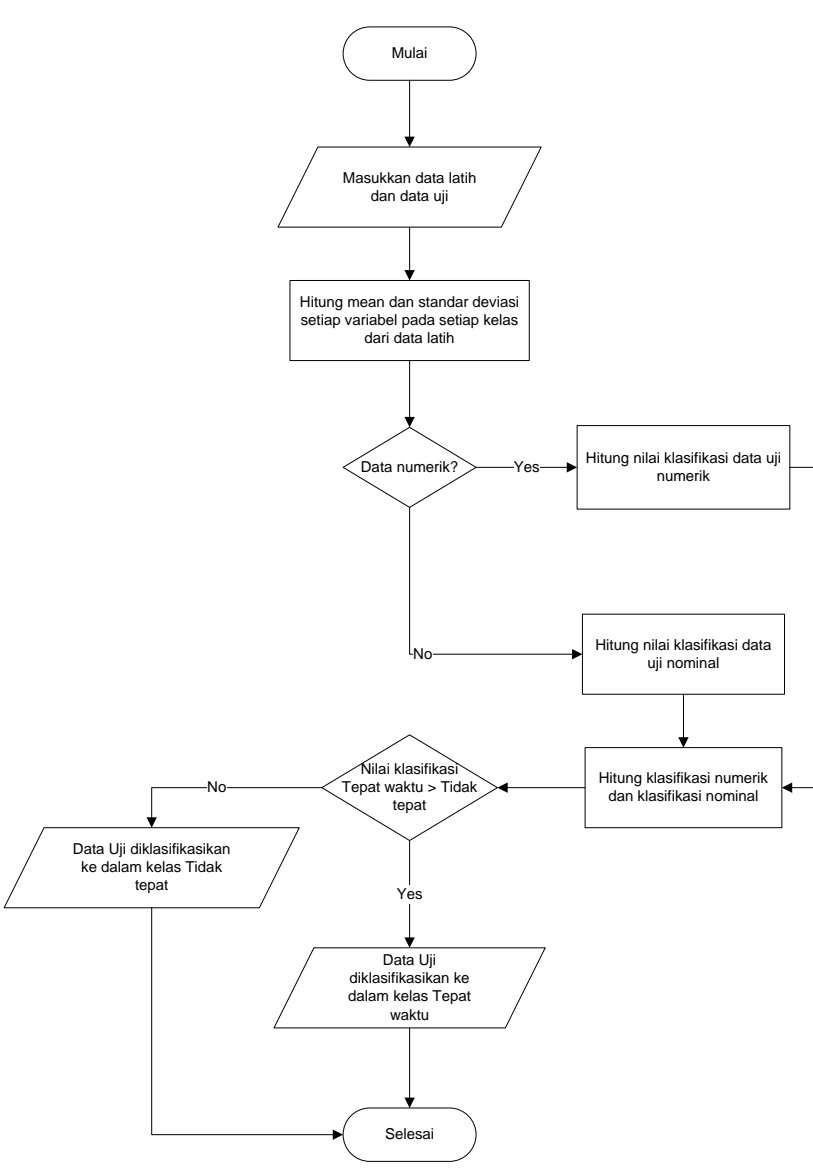

Gambar 1 Diagram alur Nä̈ve Bayes 


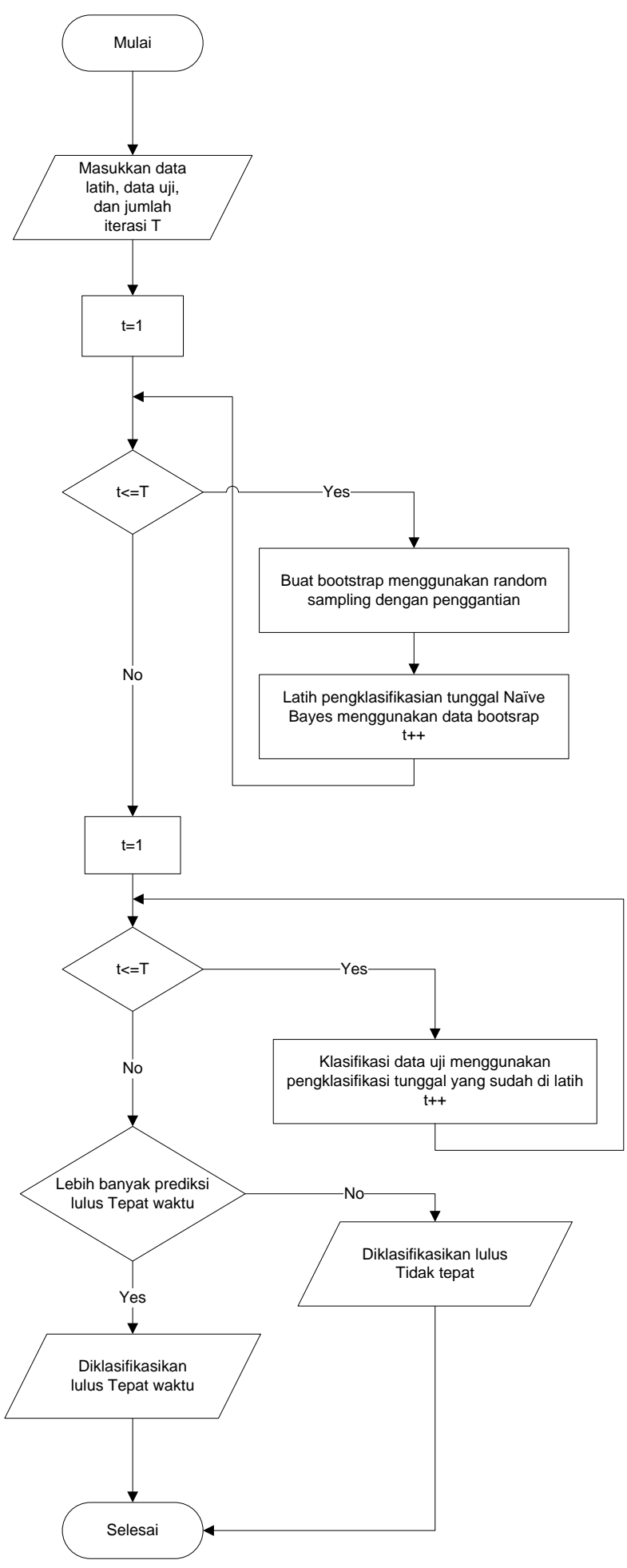

Gambar 2 Diagram Alur Bagging berbasis Naïve Bayes

\section{Metode yang Diusulkan}

Pada penelitian ini diusulkan yaitu menggunakan metode Nä̈ve Bayes. Nä̈ve Bayes merupakan teknik data mining dengan pendekatan teori probabilitas untuk membangun sebuah model klasifikasi berdasarkan pada kejadian masa lalu yang mempunyai potensi membentuk sebuah objek baru yang dikategorikan sebagai kelas yang memiliki probabilitas terbaik (Turban, Aronson, \& Liang, 2007).

Naive Bayes merupakan teknik klasifikasi dengan metode probabilitas dan statistik yang dikemukakan oleh Thomas Bayes, yaitu memprediksi peluang di masa depan berdasarkan pengalaman di masa sebelumnya sehingga dikenal sebagai Teorema Bayes. Teorema tersebut dikombinasikan dengan Naïve di mana diasumsikan kondisi antara atribut saling bebas. Klasifikasi Naive Bayes diasumsikan bahwa ada atau tidak ciri tertentu dari sebuah kelas tidak ada hubungannya dengan ciri dari kelas lainnya (Bustami, 2013).

Dalam Bayes (terutama Naive bayes), maksud independensi yang kuat adalah bahwa sebuah fitur pada sebuah data tidak berkaitan dengan ada atau tidaknya fitur lain dalam data yang sama (Kusrini \& Luthfi, 2009).

Teorema keputusan bayes adalah pendekatan statistik yang fundamental dalam pengenalan pola (pattern recognition). Naïve bayes didasarkan pada asumsi penyederhanaan bahwa nilai atribut secara kondisional saling bebas jika diberikan nilai output. Dengan kata lain, probabilitas mengamati secara bersama adalah produk dari probabilitas individu (Mujib, Suyono, \& Sarosa, 2013). Prediksi Bayes didasarkan pada teorema Bayes dengan formula umum sebagai berikut:

$$
\mathrm{P}(\mathrm{H} \mid \mathrm{X})=\frac{\mathrm{P}(\mathrm{X} \mid \mathrm{H}) \times \mathrm{P}(\mathrm{H})}{\mathrm{P}(\mathrm{X})}
$$

Penjelasan dari formula tersebut pada tabel 2.4 (Kusrini \& Luthfi, 2009).

Tabel 1 Keterangan Naïve Bayes Classifier

\begin{tabular}{|c|l|}
\hline Parameter & \multicolumn{1}{|c|}{ Keterangan } \\
\hline $\mathrm{X}$ & $\begin{array}{l}\text { Adalah data sampel dengan kelas } \\
\text { (label) yang tidak diketahui. }\end{array}$ \\
\hline $\mathrm{H}$ & $\begin{array}{l}\text { Merupakan hipotesa bahwa X } \\
\text { adalah data dengan kelas (label) } \mathrm{C}\end{array}$ \\
\hline $\mathrm{P}(\mathrm{H})$ & Adalah peluang dari hipotesa $\mathrm{H}$ \\
\hline $\mathrm{P}(\mathrm{X})$ & $\begin{array}{l}\text { Adalah peluang data sampel yang } \\
\text { diamati }\end{array}$ \\
\hline $\mathrm{P}(\mathrm{H} \mid \mathrm{X})$ & $\begin{array}{l}\text { Adalah peluang data sampel X, bila } \\
\text { diasumsikan bahwa hipotesa benar } \\
\text { (valid) }\end{array}$ \\
\hline
\end{tabular}

Jika seseorang berhadapan dengan data kontinu, asumsi khas adalah distribusi Gaussian, 
dengan parameter model dari mean dan varians. Mean, $\mu$, dihitung dengan:

$$
\mu=\frac{1}{N} \sum_{i=1}^{N} x_{i}
$$

Di mana $\mathrm{N}$ adalah jumlah sampel dan $\mathrm{xi}$ adalah nilai dari suatu contoh yang diberikan. Untuk setiap kelas $y_{j}$, probabilitas bersyarat kelas $y_{j}$ untuk fitur $X_{i}$ adalah (Salim, 2012):

$$
\mathrm{P}\left(\mathrm{X}_{\mathrm{i}}=x_{i} \mid \mathrm{Y}=y_{i}\right)=\frac{1}{\sigma_{\mathrm{ij}} \cdot \sqrt{2 \pi}} \exp ^{\frac{\left(\mathrm{x}_{\mathrm{i}}-\mu_{\mathrm{ij}}\right)^{2}}{2 \sigma i j^{2}}}
$$

Variant, $\sigma^{2}$ dihitung dengan:

$$
\sigma^{2}=\frac{1}{(N-1)} \sum_{i=1}^{N}\left(x_{i}-\mu\right)^{2}
$$

Berikut ini adalah algoritma Naïve Bayes (Mulyati, Yulianti, \& Saifudin, 2017):
a. Masukan: Data latih T, data uji $\mathrm{x}$
b. Hitung mean (rata-rata) dan standar deviasi setiap kelas
c. Hitung nilai probabilitas data uji untuk setiap kelas
d. Klasifikasikan data uji sesuai nilai probabilitas kelas yang tertinggi
e. Keluaran: Hasil klasifikasi

Untuk meningkatkan akurasi dari proses algoritma klasifikasi, salah satu cara yang dapat dilakukan adalah dengan menggunakan model prediksi yang terdiri atas banyak classifier (Tan, Steinbach, \& Kumar, 2014). Bagging (Bootstrap Agregating) adalah salah satu metode ensemble yang cara kerjanya adalah membuat beberapa sampel data baru dari data latih asli. Bagging dapat meningkatkan pengklasifikasi Naïve Bayes dan lebih baik dari pada AdaBoost (Saifudin \& Wahono, 2015). Sampel data dipilih secara acak berdasarkan distribusi uniform. Sampel data dibuat dengan cara sampling with replacement, yaitu beberapa record pada data latih yang sudah pernah diambil untuk satu sampel data bisa diambil lagi untuk sampel data tersebut, atau dengan kata lain pada satu sampel data bisa terdapat record yang nilainya sama.

Sampel himpunan data baru yang dihasilkan disebut dengan bootstrap sample. Masing-masing bootstrap sample yang dihasilkan kemudian dilatih untuk menghasilkan model klasifikasi (Nuha, Arieshanti, \& Purwananto, 2012). Uniform probability distribution berarti bahwa setiap sample dari data taraining asli memiliki kemungkinan yang sama untuk diambil. Secara rata-rata, setiap bootstrap mengandung 63\% data training asli karena setiap elemen data training memiliki peluang $1-(1-1 / \mathrm{N})^{\mathrm{N}}$ dengan $\mathrm{N}$ adalah ukuran data training (Wicaksono, Oranova $\mathrm{S}, \&$ Sawosri, 2010).
Algoritma Bagging:
a. For i=1 to $\mathrm{k}$ do // k adalah banyaknya bootstrap
b. Buat sebuah bootstrap sample $\mathrm{Di}$ berukuran $\mathrm{N}$
c. Buatlah sebuah classifier $\mathrm{Ci}$ menggunakan bootstrap sample Di
d. End For
e. $\quad \mathrm{C}^{*}(\mathrm{x})=\arg \max _{\mathrm{y}} \sum_{\mathrm{i}} \delta\left(\mathrm{C}_{\mathrm{i}}(\mathrm{x})=\mathrm{y}\right)$
f. $\quad(\delta()=1$.$) jika argumennya bernilai true$ dan sebaliknya

Algoritma bagging adalah algoritma pembuatan ensemble classifier menggunakan metode bagging. Mula-mula ditentukan dulu banyaknya bootstrap atau classifier yang akan dibuat yang ditunjukkan pada baris 1. Pada baris 2 sampai 5, untuk setiap iterasi dilakukan pembuatan bootstrap menggunakan teknik sampling with replacement dengan uniform probability distribution. Dari bootstrap yang didapatkan pada setiap iterasi, dibuat sebuah classifier untuk masing-masing bootstrap. Model prediksi yang terbentuk terdiri atas banyak classifier. Jika terdapat data yang akan diklasifikasikan atau diprediksi class labelnya, maka proses klasifikasi dilakukan dengan melakukan voting dari classifier-classifier penyusun model prediksi (Wirayuda, Hidayat, \& Shaufiah, 2010).

$\mathrm{N}$-fold cross validation merupakan salah satu metode yang digunakan untuk mengetahui rata-rata keberhasilan dari suatu sistem dengan cara melakukan perulangan dengan mengacak atribut masukan sehingga sistem tersebut teruji untuk beberapa atribut masukan yang acak. Metode cross validation memberi kesempatan yang sama pada setiap data agar tervalidasi, sehingga kumpulan pelatihan dan validasi dibuat crossover (Yulianti, 2018).

$\mathrm{N}$-fold cross validation diawali dengan membagi data sejumlah $n$-fold yang diinginkan. Dalam proses cross validation data akan dibagi dalam $\mathrm{n}$ buah partisi dengan ukuran yang sama $\mathrm{D}_{1}$, $D_{2}, D_{3}, \ldots, D_{n}$ selanjutnya proses testing dan training dilakukan sebanyak $\mathrm{n}$ kali. Cross validation merupakan pengujian standar yang 
dilakukan untuk memprediksi error rate. Setiap kelas pada data set harus diwakili dalam proporsi yang tepat antara data training dan data testing. Data dibagi secara acak pada masing-masing kelas dengan perbandingan yang sama.

Untuk mengurangi bias yang disebabkan oleh sampel tertentu, seluruh proses training dan testing diulang beberapa kali dengan sampel yang berbeda. Tingkat kesalahan pada iterasi yang berbeda akan dihitung rata-ratanya untuk menghasilkan error rate secara keseluruhan (Hastuti, 2012).

Normalisasi min-max yaitu standarisasi data dengan menempatkan data dalam range 0 sampai 1 atau -1 sampai 1 . Umumnya nilai $\mathrm{x}_{\min , \mathrm{j}}=-1$ dan $\mathrm{x}_{\text {max }, \mathrm{j}}^{\prime}=1$, atau $\mathrm{x}_{\text {min, } \mathrm{j}}^{\prime}=0$ dan $\mathrm{x}_{\text {max }, \mathrm{j}}^{\prime}=1$.

$$
\begin{gathered}
x_{i, j}^{\prime}=\left(\frac{x_{i, j}-x_{\min , j}}{x_{\max , j}-x_{\min , j}}\right)\left(x_{\max , j}^{\prime}-x_{\min , j}^{\prime}\right) \\
+x_{\min , j}^{\prime}
\end{gathered}
$$

Normalisasi z-index, membuat skala data dengan nilai deviasi yang biasanya merupakan ratarata dari nilai suatu atribut.

$$
x_{i, j}^{\prime}=\frac{x_{i, j}-\bar{\mu}_{j}}{\bar{\sigma}_{j}}
$$

Normalisasi skala desimal bekerja dengan menggeser nilai decimal hingga data memiliki satuan yang sama. Di mana $\mathrm{h}$ adalah bilangan bulat terkecil sehingga $\operatorname{Max}\left(\left|v^{\prime}\right|\right)<1$ atau dalam rentang $[-1,1]$.

$$
x_{i, j}^{\prime}=\frac{x_{i, j}}{10^{h}}
$$

\section{Hasil Dan Pembahasan}

Untuk menguji aplikasi yang telah dibuat, maka dibuat perhitungan manual terlebih dahulu, hasil hitungan manual akan dibandingkan dengan perhitungan aplikasi. Dataset yang digunakan ditunjukkan pada Tabel 2.

Tabel 2 Dataset Uji Aplikasi

\begin{tabular}{|c|c|c|c|c|c|c|}
\hline Jk & Jurusan & Selisih_th & Mtk & B.ing & B.ind & Kelulusan \\
\hline L & ipa & 0 & 6.3 & 7.8 & 7.6 & Tepat waktu \\
\hline P & ips & 0 & 6.8 & 6.2 & 7 & Tepat waktu \\
\hline P & mm & 0 & 7 & 8.6 & 6.8 & Tepat waktu \\
\hline L & mm & 0 & 7.8 & 7.8 & 7.6 & Tepat waktu \\
\hline L & ips & 0 & 8 & 5.6 & 7.4 & Tidak tepat \\
\hline P & ipa & 0 & 8 & 8.4 & 8.6 & Tepat waktu \\
\hline L & ips & 0 & 8.3 & 7.2 & 7.6 & Tidak tepat \\
\hline L & mm & 0 & 8.3 & 7.4 & 5.2 & Tidak tepat \\
\hline P & ipa & 0 & 8.3 & 8 & 8.4 & Tepat waktu \\
\hline P & ipa & 0 & 8.5 & 7.8 & 8 & Tepat waktu \\
\hline P & ips & 0 & 8.8 & 7.8 & 7.2 & Tepat waktu \\
\hline L & mm & 0 & 8.8 & 7.8 & 7.8 & Tepat waktu \\
\hline L & ipa & 0 & 9 & 8.6 & 8.6 & Tidak tepat \\
\hline L & ips & 0 & 9.5 & 5.2 & 7.6 & Tepat waktu \\
\hline L & mm & 0 & 9.8 & 7.4 & 5.6 & Tepat waktu \\
\hline P & ips & 1 & 6.5 & 7.6 & 6.4 & Tidak tepat \\
\hline P & ipa & 1 & 7.3 & 7.6 & 5.8 & Tepat waktu \\
\hline L & ips & 2 & 5.2 & 7.4 & 7 & Tidak tepat \\
\hline L & ips & 3 & 8 & 6 & 5.4 & Tidak tepat \\
\hline L & ipa & 4 & 6.7 & 6.33 & 6.83 & Tidak tepat \\
\hline
\end{tabular}

Sebelum dilakuakan perhitungan, dataset dilakukan standarisasi dengan teknik min-max dengan nilai minimal -1 dan maksimal 1 sehingga nilainya pada tipe numerik seperti Tabel 4.2.
Teknik validasi yang digunakan adalah 10-fold cross validation, sehingga dataset dibagi menjadi 10, kemudian diambil 1 data untuk dijadikan data uji kemudian sisanya dijadikan data latih. 
Tabel 3Normalisasi Dataset Numerik

\begin{tabular}{|c|c|c|c|c|}
\hline split & Mtk & b.ing & b.ind & kelulusan \\
\hline \multirow{2}{*}{1} & -0.52173913 & 0.529411765 & 0.411764706 & Tepat waktu \\
\cline { 2 - 5 } & -0.304347826 & -0.411764706 & 0.058823529 & Tepat waktu \\
\hline 2 & -0.217391304 & 1 & -0.058823529 & Tepat waktu \\
\cline { 2 - 5 } & 0.130434783 & 0.529411765 & 0.411764706 & Tepat waktu \\
\hline \multirow{2}{*}{3} & 0.217391304 & -0.764705882 & 0.294117647 & Tidak tepat \\
\cline { 2 - 5 } & 0.217391304 & 0.882352941 & 1 & Tepat waktu \\
\hline \multirow{2}{*}{4} & 0.347826087 & 0.176470588 & 0.411764706 & Tidak tepat \\
\cline { 2 - 5 } & 0.347826087 & 0.294117647 & -1 & Tidak tepat \\
\hline \multirow{2}{*}{5} & 0.347826087 & 0.647058824 & 0.882352941 & Tepat waktu \\
\cline { 2 - 5 } & 0.434782609 & 0.529411765 & 0.647058824 & Tepat waktu \\
\hline \multirow{2}{*}{6} & 0.565217391 & 0.529411765 & 0.176470588 & Tepat waktu \\
\cline { 2 - 5 } & 0.565217391 & 0.529411765 & 0.529411765 & Tepat waktu \\
\hline 7 & 0.652173913 & 1 & 1 & Tidak tepat \\
\cline { 2 - 5 } & 0.869565217 & -1 & 0.411764706 & Tepat waktu \\
\hline \multirow{2}{*}{8} & 1 & 0.294117647 & -0.764705882 & Tepat waktu \\
\cline { 2 - 5 } & -0.434782609 & 0.411764706 & -0.294117647 & Tidak tepat \\
\hline \multirow{2}{*}{9} & -0.086956522 & 0.411764706 & -0.647058824 & Tepat waktu \\
\cline { 2 - 5 } & -1 & 0.294117647 & 0.058823529 & Tidak tepat \\
\hline \multirow{2}{*}{10} & 0.217391304 & -0.529411765 & -0.882352941 & Tidak tepat \\
\cline { 2 - 5 } & -0.347826087 & -0.335294118 & -0.041176471 & Tidak tepat \\
\hline
\end{tabular}

Bagian (split) ke-1 sebagai data uji dan lainnya sebagai data latih. Pertama dilakukan perhitungan probabilitas awal masing-masing kelas tanpa memandang bukti apapun. Selanjutnya dilakukan perhitungan mean $(\mu)$ dan standar deviasi $(\sigma)$ untuk masing-masing kelas berdasarkan bukti pada setiap attribut.
Probabilitas awal

$$
\begin{aligned}
& P_{(\text {tepat wkt })}=\frac{10}{18}=0.555555556 \\
& P_{(\text {tdk tepat })}=\frac{8}{18}=0.444444444
\end{aligned}
$$

Tabel 4 Probabilitas Fitur Kelas Nominal Bagian (Split) Ke-1

\begin{tabular}{|c|c|c|c|}
\hline \multicolumn{2}{|c|}{ Jenis Kelamin } & Jurusan \\
\hline Tepat waktu & Tidak tepat & Tepat waktu & Tidak tepat \\
\hline $\mathrm{L}=4$ & $\mathrm{~L}=7$ & $\mathrm{Ipa}=4$ & $\mathrm{Ipa}=2$ \\
$\mathrm{P}=6$ & $\mathrm{P}=1$ & $\mathrm{Ips}=2$ & $\mathrm{Mm}=4$ \\
& & $\mathrm{Mm}=1$ \\
\hline $\mathrm{P}(\mathrm{JK}=\mathrm{L} \mid$ tepat $w \mathrm{kt})=4 / 10=0.4$ & $\mathrm{P}(\mathrm{JK}=\mathrm{L} \mid \mathrm{tdk}$ tepat $)=7 / 8=0.875$ & $\mathrm{P}(\mathrm{Jrsn}=\mathrm{ipa} \mid$ tepat wkt $)=4 / 10=0.4$ & $\mathrm{P}(\mathrm{Jrsn}=\mathrm{ipa} \mid \mathrm{tdk}$ tepat $)=2 / 8=0.25$ \\
$\mathrm{P}(\mathrm{JK}=\mathrm{P} \mid$ tepat $w \mathrm{wt})=6 / 10=0.6$ & $\mathrm{P}(\mathrm{JK}=\mathrm{P} \mid \mathrm{tdk}$ tepat $)=1 / 8=0.125$ & $\mathrm{P}(\mathrm{Jrsn}=\mathrm{ips} \mid$ tepat wkt $)=2 / 10=0.2$ & $\mathrm{P}(\mathrm{Jrsn}=\mathrm{ips} \mid \mathrm{tdk}$ tepat $)=5 / 8=0.625$ \\
& & $\mathrm{P}(\mathrm{Jrsn}=\mathrm{mm} \mid$ tepat $w \mathrm{wt})=4 / 10=0.4$ & $\mathrm{P}(\mathrm{Jrsn}=\mathrm{mm} \mid \mathrm{tdk}$ tepat $)=1 / 8=0.125$ \\
\hline
\end{tabular}

Tabel 5 Probabilitas Fitur Kelas Numerik Bagian (Split) Ke-1

\begin{tabular}{|c|c|c|c|c|c|}
\hline class & statistik & Selisih tahun & matematika & b.inggris & b.indonesia \\
\hline \multirow{2}{*}{$\begin{array}{c}\text { Tepat } \\
\text { waktu }\end{array}$} & $\mu$ & -0.95 & 0.382608696 & 0.435294118 & 0.258823529 \\
\cline { 2 - 6 } & $\sigma^{2}$ & 0.025 & 0.151144717 & 0.297731642 & 0.353863899 \\
\cline { 2 - 6 } & $\sigma$ & 0.158113883 & 0.38877335 & 0.54564791 & 0.594864605 \\
\hline \multirow{2}{*}{$\begin{array}{c}\text { Tidak } \\
\text { tepat }\end{array}$} & $\mu$ & -0.375 & $-3.60822 \mathrm{E}-16$ & 0.068382353 & -0.056617647 \\
\cline { 2 - 6 } & $\sigma^{2}$ & 0.625 & 0.295976235 & 0.330538186 & 0.442945502 \\
\cline { 2 - 6 } & $\sigma$ & 0.790569415 & 0.54403698 & 0.574924504 & 0.66554151 \\
\hline
\end{tabular}

Berdasarkan pembagian fold cross validation, maka data bagian (split) pertama yang dijadikan data uji dihitung sebagai berikut:

$$
\mathrm{P}\left(\mathrm{X}_{\mathrm{i}}=x_{i} \mid \mathrm{Y}=y_{i}\right)=\frac{1}{\sigma_{\mathrm{ij}} \cdot \sqrt{2 \pi}} \exp ^{-\frac{\left(\mathrm{x}_{\mathrm{i}}-\mu_{\mathrm{ij}}\right)^{2}}{2 \sigma i j^{2}}}
$$


$P(X \mid$ tepat waktu $)$

$=P(j k=L \mid$ tepat $w k t) \times P($ jurusan $=$ ipa|tepat $w k t) P($ selisih

$=-1 \mid$ tepat waktu $) \times P($ mtk

$=-0.52173913 \mid$ tepat waktu $) \times P($ b.ing

$=0.529411765 \mid$ tepat waktu) $\times P($ b. indo

$=0.411764706 \mid$ tepat waktu) $\times P($ tepat wkt $)$

$P(X \mid$ tdk tepat $)$

$=P(j k=L \mid t d k$ tepat $) \times P($ jurusan $=i p a \mid t d k$ wkt $) \times P($ selisih

$=-1 \mid t d k$ tepat $) x P(m t k$

$=-0.52173913 \mid$ tdk tepat $) \times P(b$. ing

$=0.529411765 \mid t d k$ tepat $) \times P($ b.indo

$=0.411764706 \mid$ tdk tepat $) \times P($ tdk tepat $)$

Karena probabilitas tidak tepat waktu (0.003916261) lebih besar dari pada probabilitas tepat waktu (0.001142526), maka data/record/fitur pertama diklasifikasikan lulus tidak tepat waktu. Dengan cara yang sama dilakukan perhitungan untuk data/record/fitur kedua dan seterusnya.

Tabel 6 Tabel Rekapitulasi Perhitungan Naïve Bayes

\begin{tabular}{|c|c|c|}
\hline Split & Aktual & Prediksi \\
\hline \multirow{2}{*}{1} & $\mathrm{Y}$ & $\mathrm{Y}$ \\
\cline { 2 - 3 } & $\mathrm{Y}$ & $\mathrm{Y}$ \\
\hline \multirow{2}{*}{2} & $\mathrm{Y}$ & $\mathrm{Y}$ \\
\cline { 2 - 3 } & $\mathrm{Y}$ & $\mathrm{Y}$ \\
\hline 3 & $\mathrm{~N}$ & $\mathrm{Y}$ \\
\cline { 2 - 3 } & $\mathrm{Y}$ & $\mathrm{Y}$ \\
\hline 4 & $\mathrm{~N}$ & $\mathrm{Y}$ \\
\cline { 2 - 3 } & $\mathrm{N}$ & $\mathrm{Y}$ \\
\hline 5 & $\mathrm{Y}$ & $\mathrm{Y}$ \\
\hline
\end{tabular}

\begin{tabular}{|c|c|c|}
\hline & $\mathrm{Y}$ & $\mathrm{Y}$ \\
\hline \multirow{2}{*}{6} & $\mathrm{Y}$ & $\mathrm{Y}$ \\
\cline { 2 - 3 } & $\mathrm{Y}$ & $\mathrm{Y}$ \\
\hline \multirow{2}{*}{7} & $\mathrm{~N}$ & $\mathrm{Y}$ \\
\cline { 2 - 3 } & $\mathrm{Y}$ & $\mathrm{N}$ \\
\hline \multirow{2}{*}{8} & $\mathrm{Y}$ & $\mathrm{Y}$ \\
\cline { 2 - 3 } & $\mathrm{N}$ & $\mathrm{Y}$ \\
\hline \multirow{2}{*}{9} & $\mathrm{Y}$ & $\mathrm{N}$ \\
\cline { 2 - 3 } & $\mathrm{N}$ & $\mathrm{N}$ \\
\hline 10 & $\mathrm{~N}$ & $\mathrm{~N}$ \\
\cline { 2 - 3 } & $\mathrm{N}$ & $\mathrm{N}$ \\
\hline
\end{tabular}

Berdasarkan hasil validasi Tabel 6 dibuat tabel confusion matrix seperti Tabel 7, dan dilakukan perhitungan kinerja model.

Tabel 7 Hasil Klasifikasi Perhitungan Manual Dengan 10-Fold Cross Validation

\begin{tabular}{|c|l|r|r|r|}
\hline \multicolumn{2}{|c|}{ Class } & \multicolumn{2}{c|}{ Actual } & \multirow{2}{*}{$\begin{array}{c}\text { Class } \\
\text { Precision }\end{array}$} \\
\cline { 3 - 5 } & $\begin{array}{c}\text { Tepat } \\
\text { Waktu }\end{array}$ & $\begin{array}{c}\text { Tidak } \\
\text { Tepat }\end{array}$ & Pepat \\
\hline \multirow{3}{*}{ Prediction } & $\begin{array}{l}\text { Teprion } \\
\text { Waktu }\end{array}$ & $5(\mathrm{TP})$ & $64,286 \%$ \\
\cline { 2 - 5 } & $\begin{array}{l}\text { Tidak } \\
\text { Tepat }\end{array}$ & $3(\mathrm{FN})$ & $3(\mathrm{TN})$ & $50,000 \%$ \\
\hline \multicolumn{2}{|c|}{ Class Recall } & $75,00 \%$ & $37,50 \%$ & \\
\hline
\end{tabular}

Untuk menguji aplikasi yang telah dibuat, hasil perhitungan di atas dibandingkan dengan hasil perhitungan dari aplikasi. Hasil perhitungan dari aplikasi dengan menggunakan metode Naïve bayes seperti Gambar 3.

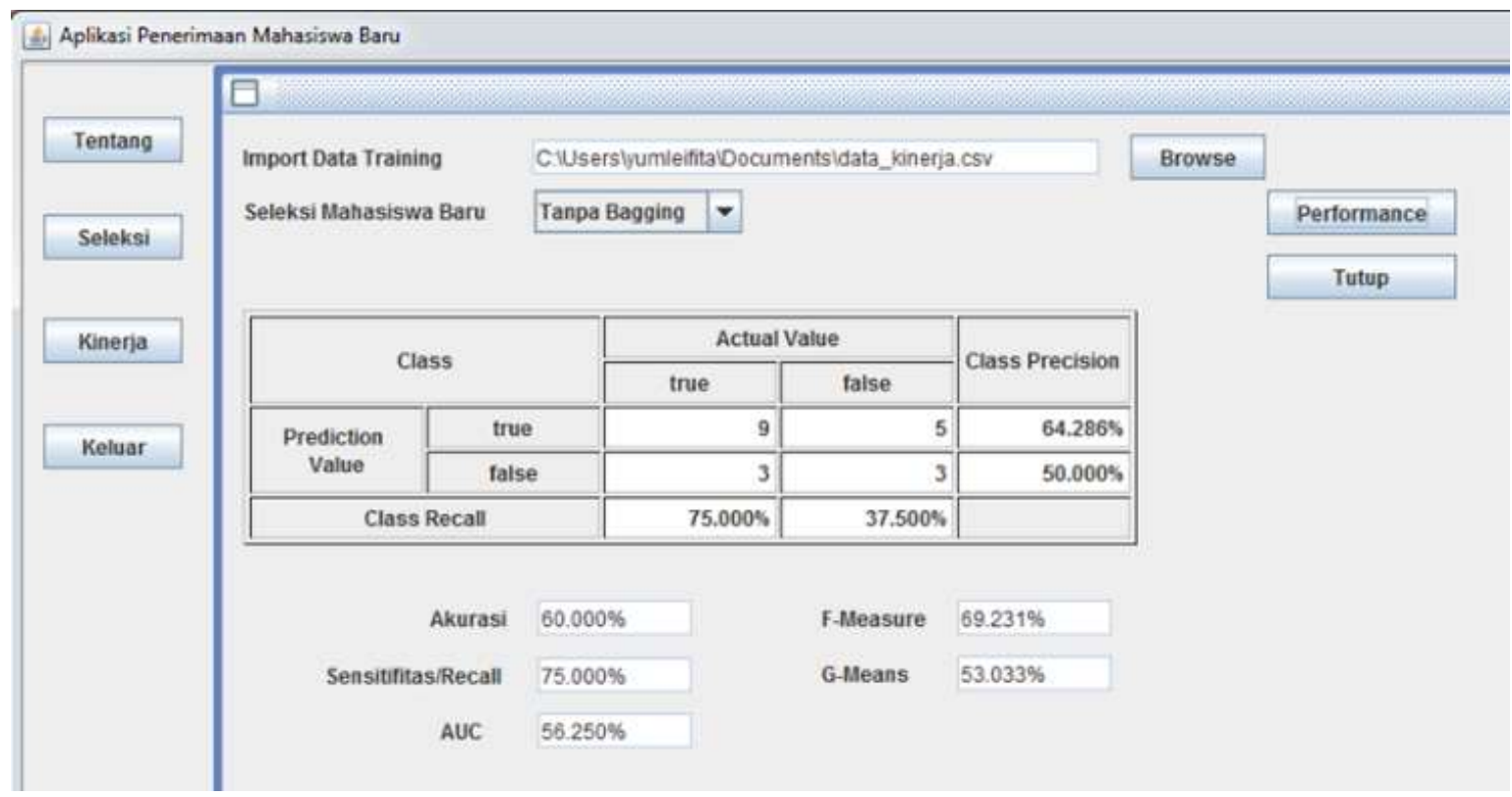

Gambar 3 Hasil Perhitungan Kinerja Model dengan Naïve Bayes 


\section{Kesimpulan}

Berdasarkan penulisan dan penelitian yang telah diuraikan, maka dapat dibuat beberapa kesimpulan yaitu:

a. Teknik data mining dapat menyeleksi mahasiswa baru dengan efektif, karena dapat memprediksi ketepatan waktu kelulusan berdasarkan data-data calon mahasiswa.

b. Boosting tidak dapat bekerja dengan baik untuk algoritma klasifikasi Naïve Bayes, dikarenakan Naïve Bayes adalah pengklasifikasian yang stabil dengan bias yang kuat (Ting \& Zheng, 2003). Adacost adalah varian lain dari Adaboost, AdaCost dapat memperbaiki teknik boosting (Sun, Kamel, Wong, \& Wang, 2007) maka perlu penelitian lanjutan pada teknik adacost sebagai perbaikan dari algoritma klasifikasi Naïve Bayes.

\section{Referensi}

Arti, Y. (2009). Penentuan Tingkat Keberhasilan Mahasiswa Tingkat I IPB Menggunakan Induksi Pohon Keputusan dan Bayesian Classifier. IPB journal, 1-37.

Baizal, Z. A., Bijaksana, M. A., \& Nasihati, I. R. (2009). Penggunaan Metode Bagging Dengan Menerapkan Data Balancing Pada Churn Prediction Untuk Perusahaan Telekomunikasi. Aplikasi Teknologi Komunikasi, 134-139.

BAN-PT. (2011). Akreditasi Institusi Perguruan Tinggi - Buku II Standar dan Presedur. Jakarta.

Bustami. (2013). Penerapan Algoritma Naive Bayes Untuk Mengklasifikasi Data Nasabah Asuransi. TECHSI:Jurnal Penelitian Teknik Informatika, 128-146.

Hastuti, K. (2012). Analisis Komparasi Algoritma Klasifikasi Data Mining untuk Prediksi Mahasiswa Non Aktif. Prosiding Semantik (pp. 241-249). Semarang: Universitas Dian Nuswantoro.

Kusrini, \& Luthfi, E. T. (2009). Algoritma Data Mining. Yogyakarta: Andi Publisher.

Mujib, R., Suyono, H., \& Sarosa, M. (2013). Penerapan Data Mining untuk Evaluasi Kinerja Akademik Mahasiswa Menggunakan Algoritma Naive Bayes Classifier. Jurnal EECCIS (Electrics, Electronics, Communications, Controls, Informatics, Systems), 7(1), 59-64.

Mulyati, S., Yulianti, Y., \& Saifudin, A. (2017). Penerapan Resampling dan Adaboost untuk Penanganan Masalah Ketidakseimbangan Kelas Berbasis Naïve Bayes pada Prediksi Churn Pelanggan. Jurnal Informatika Universitas Pamulang, 2(4), 190-199.
Nuha, M. U., Arieshanti, I., \& Purwananto, Y. (2012). Pengembangan Perangkat Lunak Prediktor Kebangkrutan Menggunakan Metode Bagging Nearest Neighbor Support Vector Machine. Jurnal Teknik POMITS, 1(1), 1-6.

Saifudin, A. (2018). Metode Data Mining untuk Seleksi Calon Mahasiswa pada Penerimaan Mahasiswa Baru di Universitas Pamulang. Jurnal Teknologi, 10(1), 25-36.

Saifudin, A., \& Wahono, R. S. (2015). Penerapan Teknik Ensemble untuk Menangani Ketidakseimbangan Kelas pada Prediksi Cacat Software. Journal of Software Engineering, l(1), 28-37.

Salim, Y. (2012). Penerapan Algoritma Naive Bayes untuk Penentuan Status Turn-Over Pegawai. Media Sains, 4(2), 196-205.

Sun, Y., Kamel, M. S., Wong, A. K., \& Wang, Y. (2007). AdaCost : Misclassification Cost-Sensitive Boosting. Pattern Recognition 40, 3358-3378.

Tan, P.-N., Steinbach, M., \& Kumar, V. (2014). Introduction to Data Mining. Essex: Pearson Education Limited.

Ting, K. M., \& Zheng, Z. (2003). A Study Of AdaBoost With Naive Bayesian Classifiers : Weakness and Improvement. Computational Intelligence, Volume 19, Number 2, 186-199.

Turban, E., Aronson, J. E., \& Liang, T. P. (2007). Decision Support Systems and Intelligent Systems (7 ed.). Yogyakarta: Andi Publisher.

Wicaksono, S. A., Oranova S, D., \& Sawosri. (2010). Pembangunan Model Prediksi Defect Menggunakan Metode Ensemble Decision Tree dan Cost Sensitive Learning. Jurnal EECCIS Vol.IV No.1, 1-7.

Wirayuda, T. A., Hidayat, D., \& Shaufiah. (2010). Analisis Dan Implementasi Metode Bootstrap Aggregating (Bagging) Pada Model Artificial Neural Network Dengan Studi Kasus Klasifikasi Penanganan Tindak Lanjut Pasien Unit Gawat Darurat. posiding ITT, 1-9.

Yulianti. (2018). Metode Data mining Untuk prediksi Churn Pelanggan. Jurnal ICT Akademi Telkom Jakarta, 9(16), 46-52.

Zhang, H., \& Su, J. (2006). Learning Probabilistic Decision Trees For AUC. Pattern Recognition Letters 27, 892-899. 